\title{
ИНФОРМАЦИОННОЕ ВЗАИМОДЕЙСТВИЕ МЕДИЦИНСКОЙ ГРИД-СИСТЕМЫ С ЭЛЕКТРОННЫМ РЕЕСТРОМ ПАЦИЕНТОВ
}

\author{
В. В. Вишневский \\ Институт проблем математических машин и систем НАН Украины
}

\begin{abstract}
We discuss architectural solutions for the storage of diagnostic information in medical grid systems. Information interaction of different systems at the national level can greatly simplify the solutions for storing large amounts depersonalize diagnostic data.
\end{abstract}

Большинство аналитических изданий последние 10 лет фиксируют небывалый информационный взрыв во всех сферах деятельности человека, включая и медицинскую диагностику. Вывод о том, что “за последние несколько лет накоплено информации больше, чем за все предыдущие 40 тыс. лет" сегодня цитируется любым популярным журналом. При этом в практическом здравоохранении можно зафиксировать явное противоречие между достаточно распространенным цифровым диагностическим оборудованием и архаическим по форме и содержанию бумажным документооборотом медицинских записей. Действительно, при бумажной форме документооборота проблема информационного взрыва может нас не волновать, поскольку цифровые данные просто уничтожаются в момент документирования на бумажном носителе.

В работах $[1,2]$ показаны пути решения проблемы накопления и длительного хранения диагностической информации в так называемых грид-системах медицинского назначения. При этом, в качестве примера действующей грид-системы медицинского назначения выбран наиболее известный и рутинный телеметрический сигнал - электрокардиограмма покоя (проект «Медгрид»).

Первичной информацией для проекта «Медгрид» являются электрокардиограммы, получаемые с помощью сертифицированных цифровых кардиографов в специализированных медицинских учреждениях.

Грид-хранилища проекта «Медгрид» позволяют накапливать деперсонализированные цифровые электрокардиограммы в европейском формате SCP-ECG в масштабе популяции всей страны и обеспечивать обработку этой информации для целей практического здравоохранения и для научных исследований.

Важно отметить, что в силу специфики организации распределенных грид-хранилищ и грид-кластеров, которые юридически принадлежат разным государственным организациям, диагностическая информация может храниться только в деперсонализированном виде.
С одной стороны, отсутствие в диагностических файлах персональных данных о пациенте позволяет снимать вопросы защиты этих персональных данных от несанкционированного доступа. При этом для обработки диагностических данных в целях научных исследований или оценки диагностических решений персональные данные вовсе не обязательны.

С другой стороны, работа с деперсонализированными диагностическими данными существенно затруднена на этапе привязки этих данных к записям в метабазе грид-хранилища, которая обычно строится на принципах реляционной СУБД. По сути, врач, посылающий в медицинскую грид-систему очередную порцию деперсонализированных диагностических данных, не имеет четких объективных критериев для привязки этих данных к тому или иному пациенту в метабазе грид-системы. Выходов из данной проблемы два-либо необходимо идентифицировать пациента по его телеметрическому сигналу, что весьма трудоемко в вычислительном плане, либо в передаваемых в грид-систему файлах должны содержаться уникальные идентификаторы, единые для всей страны.

До сих пор ни одна из распространенных на рынке медицинских информационных систем (МИС) уровня поликлиники или стационара не могла гарантировать наличие единого идентификатора пациента по той простой причине, что методика формирования такого идентификатора в Украине отсутствует. Ситуация может измениться в связи с развернутыми работами по созданию МОЗ Украины нового национального реестра под названием «Электронный реестр пациентов» (ЭРП). Одной из важных задач ЭРП как раз и является автоматизация процесса формирования уникального идентификатора пациента, который будет использоваться всеми МИС на уровне региональных учреждений здравоохранения [3].

На рисунке 1 показана возможная схема информационного взаимодействия грид-системы с ЭРП, которая разрешает описанную выше проблему и позволяет сохранять диагностические данные, посту-

(ㄷ) В. В. Вишневский 


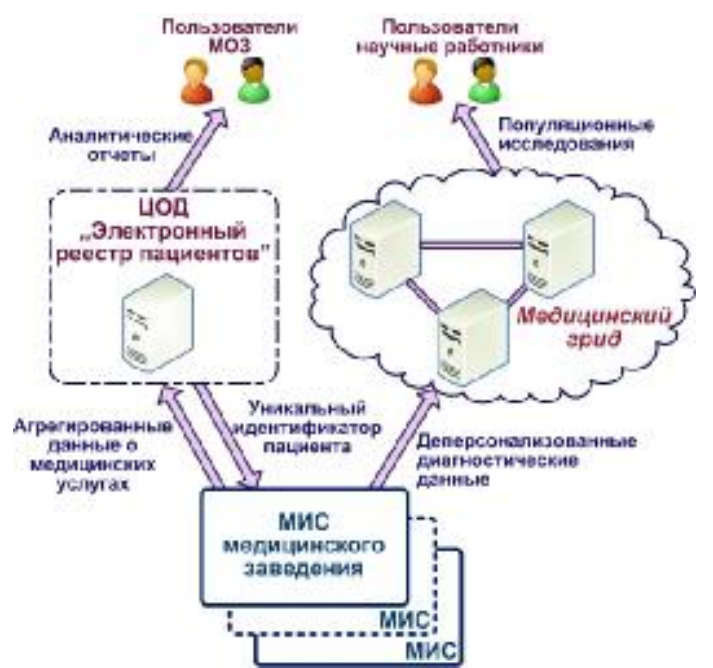

Puc.1. Схема информационного взаимодействия грид-системы и ЭРП.

пающие из МИС, с полной автоматизацией привязки этих деперсонализированных данных к пациенту в метабазе грид-хранилища.

Архитектура информационного взаимодействия такова. Технологические регламенты ЭРП обеспечивают для МИС всех типов выдачу уникального идентификатора пациента, который должен использоваться при любых внешних транзакциях этих МИС при обмене медицинскими записями. Сам электронный реестр накапливает и обрабатывает лишь агре-

\section{Литература}

1. Медицинская ГРИД-система на базе электрокардиограмм: новый инструмент для клинической кардиологии и популяционных исследований / Вишневский В. В., Чайковский И. А., Киржнер Г. Д. [и др.] // Международный научно-практический журнал "Кардиология: от науки к практике”. -2012. -№ 2.-С. 108-116.

2. Вишневский В. В. Грид-система для массового накопле- гированные данные о медицинских услугах, которые предоставлены пациенту в том или ином медицинском учреждении. А вот цифровые медицинские данные передаются, накапливаются длительное время и обрабатываются в медицинской грид-системе национального уровня. При передаче диагностических данных персональные данные о пациенте удаляются, однако в обязательном порядке используется уникальный идентификатор пациента. Такое решение потребует минимальных изменений как на уровне МИС, так и на уровне уже существующего проекта Медгрид. При этом все трудности, связанные со связыванием диагностических данных с тем или иным пациентом, будут устранены и полностью автоматизированы.

Выводы. В настоящее время в Украине имеются все необходимые ресурсы для обеспечения длительного хранения цифровых диагностических данных. Однако для разрешения возможных трудностей при обработке деперсонализированных данных в грид-хранилищах необходимо организовать взаимодействие с электронным реестром пациентов в части формирования уникального идентификатора пациента. На наш взгляд, организация такого информационного взаимодействия позволит вывести организацию здравоохранения в Украине на новый технологический уровень.

ния и обработки цифровых электрокардиограмм / В. В. Вишневский // Український журнал телемедицини та медичної телематики. -2013. - Т. 11, № 1. - С. 202-208.

3. Голубчиков М. В. Електронний реєстр пацієнтів-етапи створення / Голубчиков М. В., Коваленко О. С., Ярменчук I. А. // Український журнал телемедицини та медичної телематики. -2013. - Т. 11, № 1.-С. 145-147. 